\title{
Preparation of Nanostructured Catalysts by Grafting Metal Alkoxides on the Surface of Oxides Supports and their Performances in Some Reactions of Industrial Interest
}

ISSN: 2637-8035

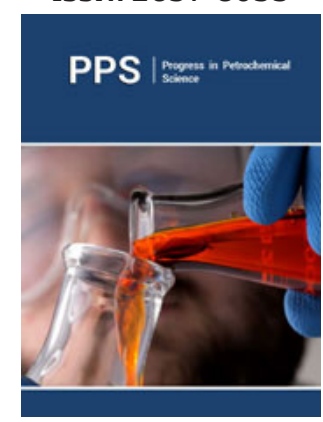

*Corresponding author: E Santacesaria, Eurochem Engineering srl, Via Codogno 5 (IT-20139) Milano, Italy

Submission: 喟 April 16, 2020

Published: 此 May 01, 2020

Volume 3 - Issue 2

How to cite this article: E Santacesaria, M Cozzolino, R Tesser, M Di Serio. Preparation of Nanostructured Catalysts by Grafting Metal Alkoxides on the Surface of Oxides Supports and their Performances in Some Reactions of Industrial Interest. Progress Petrochem Sci .3(2). PPS.000560.2020. DOI: $10.31031 /$ PPS.2020.03.000560

Copyright@ E Santacesaria, This article is distributed under the terms of the Creative Commons Attribution 4.0 International License, which permits unrestricted use and redistribution provided that the original author and source are credited.

\author{
E Santacesaria ${ }^{1 *}$, M Cozzolino $^{2}$, R Tesser ${ }^{3}$ and M Di Serio ${ }^{3}$ \\ ${ }^{1}$ Eurochem Engineering srl, Via Codogno 5 (IT-20139) Milano, Italy \\ ${ }^{2}$ Eni SpA, Refining \& Marketing Manager, Italy \\ ${ }^{3}$ Department of Chemica Sciences, University FEDERICO II of Naples, Italy
}

\begin{abstract}
Metal alkoxide grafting technique can be used for changing the acid-base and/or the redox properties of the surface of an oxide rich in hydroxyls. The preparation of catalysts by grafting different commercial available alkoxides, such as: $\mathrm{Si}, \mathrm{Ti}, \mathrm{Zr}$, and $\mathrm{V}$ on the surface of oxides, such as: $\mathrm{SiO}_{2}, \mathrm{Al}_{2} \mathrm{O}_{3}$ and $\mathrm{TiO}_{2}$, is reviewed. The performances of the acid catalysts were evaluated by adequate test reactions such as: methanol dehydration, skeletal isomerization of 1-butene and alkane isomerization and cracking. The redox properties of vanadium based catalysts, obtained by grafting vanadyl alkoxide on $\mathrm{SiO}_{2}$ and $\mathrm{TiO}_{2} / \mathrm{SiO}_{2}$ supports, have been tested in reactions, such as: the $\mathrm{SCR}$ of $\mathrm{NO}$ with $\mathrm{NH}_{3}$, the Oxidative Dehydrogenation $(\mathrm{ODH})$ of ethanol and methanol to formaldehyde and acetaldehyde, the ODH of propane, isobutane and n-butane.
\end{abstract}

Keywords: Grafting; Metal alkoxides; Silica; Alumina; Titania; Vanadia

\section{Introduction}

Metal alkoxides are nowadays largely employed for preparing ceramic materials, for thin coating films and for supports and catalysts preparation using in the different cases the solgel technique or the chemical vapour deposition [1]. Although very promising, less popular is the employment of metal alkoxides for preparing supports and catalysts by using the grafting technique. This technique can usefully be used for deeply changing the acid-base and/or the redox properties of the surface of an oxide rich of hydroxyls. As the catalytic properties depends almost exclusively on the surface properties of the solid used as catalyst, modifying opportunely the surface by contacting it with reactive substances like the metal alkoxides can give surprising results in terms of activity and selectivity in different reactions. In particular, the properties of the new surfaces obtained by reacting the superficial hydroxyls with a metal alkoxide, after a stabilizing treatment of hydrolysis and calcinations, are quite different from the original surface. A systematic work has been made on the subject by our research group in the past and a review of the most significant obtained results is reported in this paper.

\section{Summary of the properties of some alkoxides affecting the grafting procedure}

Metal alkoxides are characterised by the presence of M-O-C bonds. Due to the strongly electronegative character of oxygen (3.5 in the Linus Pauling electronegativity scale) the ionic character of the metal-oxygen bond would be preminent.

$$
{ }_{\mathrm{M}}^{+} \boldsymbol{\Omega}^{\delta-}-\mathrm{C}
$$

Metal alkoxides exhibit both Lewis and base properties. It could be expected $80 \%$ of ionic character for the more electropositive metals (electronegativity in the range 0.9-1.2, that is, 
alkaly metals, alkaline earths and lanthanons, while, it could be expected $65 \%$ of ionic character for metals having electronegativity values in the range 1.3-1.5 such as in the case of aluminium, titanium and zirconium [2].

However, some of the mentioned alkoxides show a fair degree of volatility and solubility in common organic solvents, that is, have properties which can be considered characteristics of covalent compounds. The attenuation of the polarity of the metal-oxygen bond can be attributed to two main factors:

(i) The inductive effect (electron release) of the alkyl or aryl group bonded to the oxygen.

(ii) The formation of oligomers through dative bonds of the type<smiles>C=[W]1(C)O[Al](C)(C)O1</smiles>

The oligomerization of alkoxide complexes $\left[\mathrm{M}(\mathrm{OR})_{\mathrm{n}}\right]_{\mathrm{x}}$ depends on a number of factors such as:

A. The electrophilic nature of the metal center. More electron deficient metal centers favour the formation of highly oligomerized species.

B. The size of the metal atom. Larger atoms tend to attain higher coordination number through intermolecular association involving alkoxo bridging.

C. The steric demand of the alkoxide groups. More sterically hindered alkoxo ligands would favour the formation of less associated species.

D. The electron-withdrawing or donating nature of the substituent on the oxygen atom. Electron withdrawing substituents reduce the electron density on the oxygen atom rendering it less prone to the formation of bridges.

Bradley [2] suggested the following rules:

a. Alkoxides adopt the smallest possible structural unit consistent with all atoms attaining a higher coordination number;

b. Oxygen atom coordination number should not exceed 4 .

c. The degree of association can be assumed only on the basis of the stereochemistry of the central metal atom.

Examples of aluminium alkoxides association are reported below:
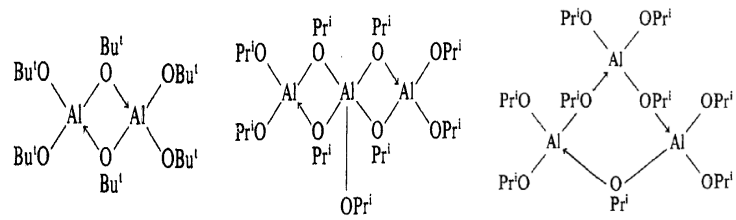

Silicon and Germanium alkoxides are all monomeric (see Mehrotra et al. [3]).

\section{Summary of the properties of some oxide surface that can be used as support for grafting}

Alumina is an amphoteric oxide with a moderate basic character having a ZPC (Zero Point Charge) = 8-9. According to Peri [4], on the alumina surface there are 5 different type of hydroxyls A, B, C, D and $\mathrm{E}$, as it can be seen in Figure 1. The difference is given by the number of groups $\mathrm{O}_{2}^{-}$surrounding the hydroxyls and clearly these hydroxyls have different acid-base characters.

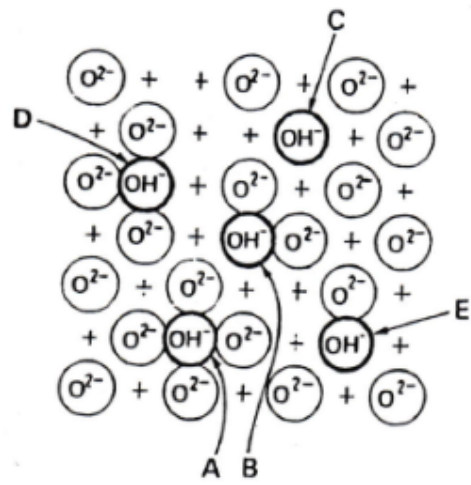

Figure 1: Different types of hydroxyls on the surface of alumina [4].

Moreover, Tanabe [5] has demonstrated that on alumina there are both acid sites of Bronsted \& Lewis character in an approximately equal amount. However, considering an amphoteric oxide in acid environment the hydroxyls of the support will react as it follows

$$
\mathrm{S}^{-} \mathrm{OH}+\mathrm{H}^{+} \mathrm{A}^{-} \leftrightarrow \mathrm{S}^{-} \mathrm{OH}_{2}^{+} \mathrm{A}^{-}
$$

On the contrary, in a basic environment the reaction will be:

$$
\mathrm{S}^{-} \mathrm{OH}+\mathrm{B}^{+} \mathrm{OH}^{-} \leftrightarrow \mathrm{SO}^{-} \mathrm{B}^{+}+\mathrm{H}_{2} \mathrm{O}
$$

The hydroxyls on the silica surface are more uniform and have a moderately acid character being the $\mathrm{ZPC}=1-2$. No Lewis acid sites are present.

\section{Description of the grafting technique}

The grafting technique [6-8] consists in putting in contact a metal alkoxide pure or dissolved in a opportune solvent with the surface of an oxide rich of hydroxyls. By grafting a metal alkoxide on a support it is possible:

A. Change of the hydrophilic/hydrophobic character of the surface;

B. To put a desired reactive group on the surface of a support;

C. To obtain a well dispersed oxide on the surface of another one by using a low ratio alkoxide/support, so modifying the acidbase or redox properties of the surface; 
D. A monolayer or a multilayer film of an oxide on the surface of another one;

E. To anchor another metal on a mono/multilayered already coated system (example vanadia supported on titania coating silica with a monolayer or multilayer.

The grafting operation occurs through three different steps that are:

A. Grafting: Reaction between the metal alkoxide and the superficial hydroxyls. This reaction can occur with different a stochiometry according to the type of alkoxide employed and the surface density of the hydroxyls:

$$
\begin{aligned}
& \mid \mathrm{OH}+\mathrm{Me}(\mathrm{OR})_{\mathrm{n}} \quad \rightleftarrows \quad-\mathrm{OMe}(\mathrm{OR})_{\mathrm{n}-1}+\mathrm{ROH}
\end{aligned}
$$

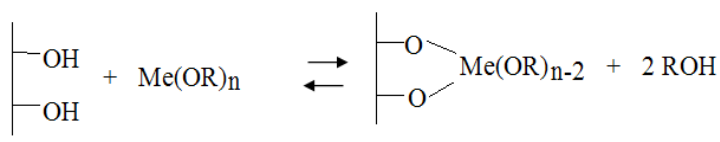

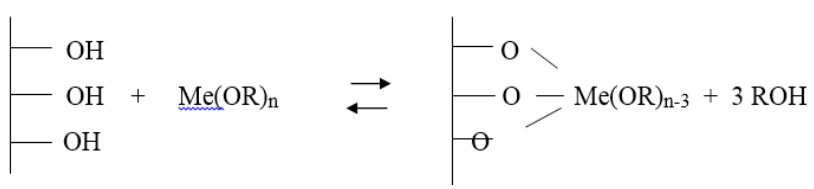

B. Steaming or burning: Have the scope of stabilizing the obtained surface eliminating the organic groups bonded to the grafted metal.

$$
\left|\mathrm{OMe}(\mathrm{OR})_{\mathrm{n}-1}+(\mathrm{n}-1) \mathrm{H}_{2} \mathrm{O} \longrightarrow\right| \mathrm{OMe}(\mathrm{OH})_{\mathrm{n}-1}+(\mathrm{n}-1) \mathrm{ROH}
$$

C. Calcination: A dehydration occurs and the original oxide surface is more or less coated with another different oxide. Metal alkoxides eventually can also be modified before grafting for a better control of the properties of the heterogenized catalytic site:

a. By changing the alkoxide groups through equilibrium exchange reactions of the type:

$$
\mathrm{Me}(\mathrm{OR})_{\mathrm{n}}+\mathrm{nR}^{\prime} \mathrm{OH} \rightleftarrows \mathrm{Me}\left(\mathrm{OR}^{\prime}\right)+\mathrm{n} \mathrm{ROH}
$$

b. By introducing other elements changing the electron density on the metal. An example is:

$$
\mathrm{Zr}(\mathrm{OR})_{4}+\mathrm{H}_{2} \mathrm{SO}_{4}(100 \% \mathrm{wt}) \rightarrow \mathrm{Zr}(\mathrm{OR})_{2} \mathrm{SO}_{4}+2 \mathrm{ROH}
$$

So, generating by grafting very strong acid sites.

c. By condensing a metal alkoxide with another one through a chemical reaction such as, for example, the one originated by the partial hydrolysis. That is, by preparing and then grafting heterometallic alkoxide compounds.
An example of the preparation of hetero-metallic alkoxide, that is, the "active site" is prepared in homogeneous phase and then heterogenized is the one proposed by Rulkens et al. [9]:
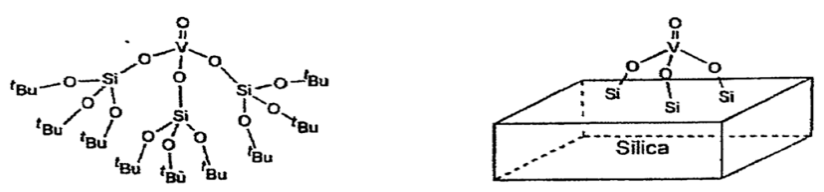

The main factors influencing the grafting reaction are:

a. The chemical properties and structure of the alkoxide;

b. The chemical properties and the structure of the solid surface;

c. The choice of the alkoxide solvent (polar, apolar, none). Often the parent alcohol is used as a solvent. This choice, normally, has a detrimental effect on the grafting yields by affecting the equilibrium reaction:

$$
\text { Supp-OH } \left.+\mathrm{Me}(\mathrm{OR})_{\mathrm{n}} \rightleftarrows \text { Supp-M(OR }\right)_{\mathrm{n}}+\mathrm{ROH}
$$

d. The alkoxide concentration. Must be chosen on the base of the hydroxyl density of the solid support.

e. The volume of the solution.

f. The amount of solid support

g. The temperature of the reaction. The alternatives are usually the room temperature or the solvent boiling temperature.

h. The time of the reaction.

i. The stirring rate.

\section{System Studied and Achieved Results}

Many different catalysts have been prepared using the grafting technique starting from some different commercial available alkoxides, such as: silicon, titanium, zirconium and vanadium anchored on the surface of oxides, such as: $\mathrm{SiO}_{2}, \mathrm{Al}_{2} \mathrm{O}_{3}$ and $\mathrm{TiO}_{2}$. All the employed supports and the prepared catalysts have been characterized by using different techniques to evaluate the change of the acid-base or redox properties of the surface. Then, the prepared catalysts were submitted to adequate test reactions such as: methanol dehydration, skeletal isomerization of 1-butene to isobutene and alkane isomerization and cracking for what concerns the acid catalysts, while, the test reactions for the redox properties were: the SCR (Selective Catalytic Reduction) of NO with $\mathrm{NH}_{3}$, the Oxidative Dehydrogenation (ODH) of ethanol and methanol to formaldehyde and acetaldehyde and the ODH of propane, isobutane and n-butane. Very promising results have been obtained in some of the mentioned reactions as a consequence of the peculiarity of the catalysts obtained with the alkoxide grafting technique. The most relevant obtained results will be reported in this work by considering separately both the acid-base and redox catalysts. 


\section{Preparation and testing of catalysts with appropriate acid-base properties}

The catalyst with acid properties prepared by grafting are summarized in Table 1 together with some peculiar aspect used in the preparation and the reactions test used for their characterization.

Table 1: List of acid-base catalysts prepared by grafting and corresponding test reactions.

\begin{tabular}{|c|c|c|c|c|}
\hline No. & Grafted alkoxide & Solvent & Support & Test Reaction \\
\hline 1 & $\mathrm{Si}(\text { Ethoxide })_{4}$ & none & $\mathrm{Al}_{2} \mathrm{O}_{3}$ & $\begin{array}{c}\text { Skeletal } \\
\text { isomerization of } \\
\text { isobutene }\end{array}$ \\
\hline 2 & $\mathrm{Zr}(\text { n-butoxide })_{4}$ & butanol & $\mathrm{Al}_{2} \mathrm{O}_{3}$ & $\begin{array}{c}\text { Methanol } \\
\text { dehydration to } \\
\text { dimethyl ether }\end{array}$ \\
\hline 3 & $\mathrm{Ti}(\text { iso-OPr })_{4}$ & toluene & $\mathrm{SiO}_{2}$ & $\begin{array}{c}\text { Methanol } \\
\text { dehydration to } \\
\text { dimethyl ether }\end{array}$ \\
\hline 5 & $\mathrm{Al}\left(\right.$ iso-OPr) $\mathrm{SO}_{4}$ & toluene & $\mathrm{SiO}_{2}$ & $\begin{array}{c}\text { Cracking and } \\
\text { isomerization of } \\
\text { n-hexane }\end{array}$ \\
\hline 5 & $\mathrm{Zr}\left(\mathrm{OC}_{8} \mathrm{H}_{17}\right) 2 \mathrm{SO}_{4}$ & toluene & $\mathrm{SiO}_{2}$ & $\begin{array}{c}\text { Cracking and } \\
\text { isomerization of } \\
\text { n-hexane }\end{array}$ \\
\hline
\end{tabular}

This reaction occurs in two steps that are:

a. Skeletal isomerisation of 1-butene [7]:

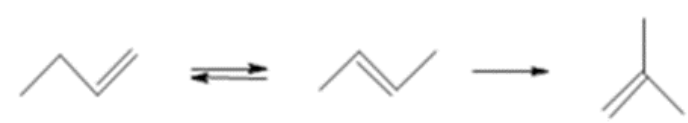

This reaction occurs in two steps that are:

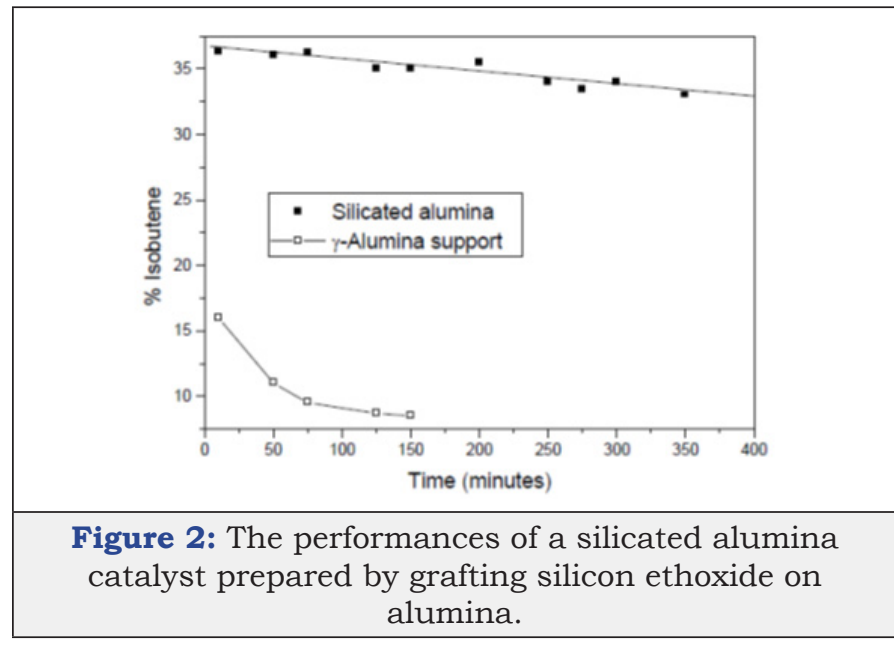

The double bond shifting requiring weak Bronsted acid sites and the skeletal isomerisation requiring Bronsted acid sites of medium strength. The presence of strong acid sites, in particular Lewis acid sites, gives place to catalyst deactivation for the formation of coke. The best catalyst resulted a silicated alumina. The catalyst was prepared by contacting a $\gamma$-alumina support of $180 \mathrm{~m}^{2} / \mathrm{g}$ with silicon tetraethoxide (TEOS) Relevant results of both activities and selectivities have been achieved, by using the mentioned acidic catalyst and the performance can be appreciated in Figure 2 compared with the original $\gamma$-alumina support.

The best catalyst obtained by grafting contained 3\% of silica corresponding approximately to the coating of a monolayer. The value of ZPC equal to 7.5 for the support decreased to 5.6 after the silica deposition and the intrinsic surface ionization constants strongly decreased too (pK1 from 5.7 to 3.4 and pK2 from 9.3 to 7.6). At last, the hydroxyls density, evaluated by Thermo Gravimetric Analysis, consistently increased from 1.05 to $1.4 \mathrm{mmol} / \mathrm{g}$ suggesting a combination of the two following reactions stoichiometry:
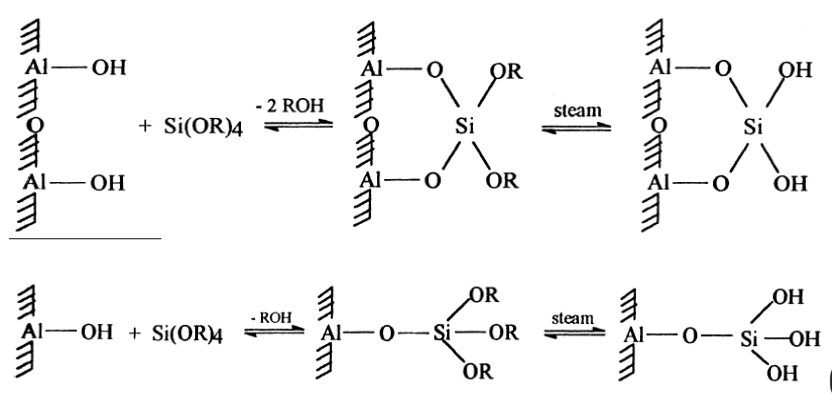

Methanol dehydration to dimethylether [7]:

$$
2 \mathrm{CH}_{3} \mathrm{OH} \rightarrow \mathrm{CH}_{3} \mathrm{OCH}_{3}+\mathrm{H}_{2} \mathrm{O}(11)
$$

A good performance has been obtained by using a catalyst prepared by grafting zirconium tetra n-butoxide on a $\gamma$-alumina of $180 \mathrm{~m}^{2} / \mathrm{g}$. The optimal concentration of zirconium on the support was $0.08 \mathrm{mmol} / \mathrm{g}$. By increasing the amount of grafted zirconia the basic character of the catalyst increased and a hydroxyls density reached a maximum in correspondence of the maximum catalytic activity. This suggest a 1:1 stoichiometry for the grafting reaction, that is:
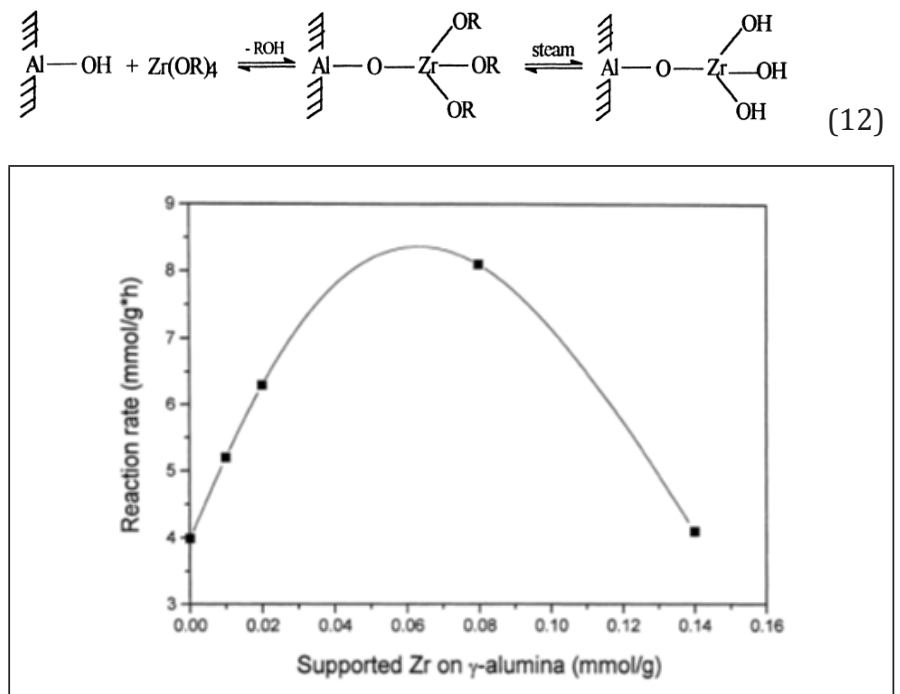

Figure 3: Activities in methanol dehydration as a function of the amount of zirconia grafted on alumina.

Probably, the increase of both the basicity of the active sites and the hydroxyl density is responsible of the activity increase. However, 
despite the very small amount of grafted zirconia the reaction rate is doubled if compared with the activity shown by $\gamma$-alumina as it can be appreciated in Figure 3.

A similar behaviour has been obtained by grafting titanium iso-propoxide on a silica support of $450 \mathrm{~m}^{2} / \mathrm{g}$, that is, the activity almost null on silica, strongly increased by increasing the amount of grafted titania until reaching a maximum of $0.95 \mathrm{mmol} / \mathrm{hg}$ for a catalyst containing $1.8 \mathrm{mmol} / \mathrm{g}$ of grafted titania corresponding approximately to a mono-layered coating [8]. The specific surface area was slightly reduced from 450 to $400 \mathrm{~m}^{2} / \mathrm{g}$ after the grafting procedure and the same occurred for the hydroxyls density decreasing from 2.2 to $1.9 \mathrm{mmol} / \mathrm{g}$. Both acid and basic sites are present on the surface that has a cooperative effect in promoting the methanol dehydration reaction.

1) Cracking and isomerisation of n-hexane $[6,8]$

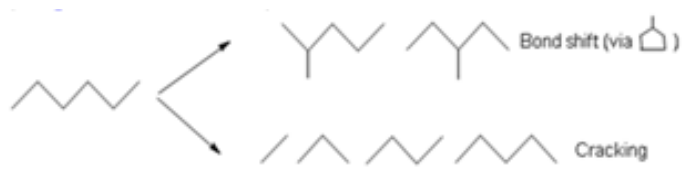

This reaction requires very strong acid sites. At this purpose, two different catalysts have been prepared by grafting respectively sulphated aluminium and sulphated zirconium alkoxide. Sulphated derivatives of both aluminium and zirconium alkoxides were prepared by adding pure sulphuric acid (100\% b.w.) drop by drop to the alkoxide solution in toluene at room temperature. The occurring reaction is:

$$
\mathrm{M}(\mathrm{OR}) \mathrm{n}+\mathrm{H}_{2} \mathrm{SO}_{4} \rightarrow \mathrm{M}(\mathrm{OR})_{\mathrm{n}-2} \mathrm{SO}_{4}+2 \mathrm{ROH}
$$

While, Aluminium Isopropoxide was directly submitted to this reaction, zirconium tetra n-butoxide was preliminarily submitted to an exchange reaction with 1-Octanol, that is:

$$
\mathrm{Zr}\left(\mathrm{OC}_{4} \mathrm{H}_{9}\right)_{4}+4 \mathrm{CH}_{3}\left(\mathrm{CH}_{2}\right) 7 \mathrm{OH} \rightarrow \mathrm{Zr}\left(\mathrm{OC}_{8} \mathrm{H}_{17}\right)_{4}+4 \mathrm{C}_{4} \mathrm{H}_{9} \mathrm{OH}
$$

The grafting of the sulphated alkoxides gives place to the following surface reaction:

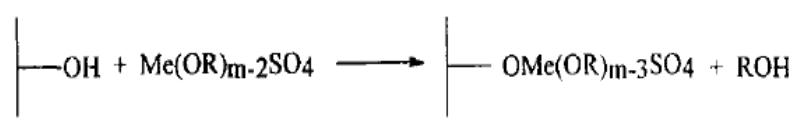

After steaming and calcinations these catalysts give place to very strong acid sites. In particular, it is well known that Sulphated Zirconia catalysts are characterized by super acidity and it must be taken into account that the catalyst prepared by grafting are different with respect to the ones obtained by doping zirconia. Both the prepared catalysts have shown activity in cracking and isomerizing n-hexane at relatively low temperature of $250{ }^{\circ} \mathrm{C}$ after a pre-treatment at $400^{\circ} \mathrm{C}$ in air for two hours. The two catalysts, as expected, deactivated in few time and heated in dry air, at $500{ }^{\circ} \mathrm{C}$, for restoring the activity the Sulphated alumina showed an increase of the activity, while, on the contrary Sulphated zirconia completely loses the activity.

\section{Preparation and testing of catalysts with redox properties}

The catalyst with redox properties, prepared by grafting, are summarized in Table 2 together with some peculiar aspect used in the preparation and the reactions test used for their characterization.

Table 2: List of the redox catalysts prepared by grafting

\begin{tabular}{|c|c|c|c|c|}
\hline No. & Grafted alkoxide & Solvent & Support & Test Reaction \\
\hline 1 & $\mathrm{Ti}$ (iso-OPr) ${ }_{4}$ & Toluene & $\mathrm{SiO}_{2}$ & \multirow{7}{*}{$\begin{array}{l}\text { Cyclo-octene } \\
\text { epoxidation }\end{array}$} \\
\hline 2 & $\mathrm{Ti}$ (iso-OPr) ${ }_{4}$ & Dioxane & $\mathrm{SiO}_{2}$ & \\
\hline 3 & $\mathrm{Ti}(\text { iso-OPr })_{4}$ & Isopropanol & $\mathrm{SiO}_{2}$ & \\
\hline 4 & VO (Iso-OPr) $)_{3}$ & Dioxane & $\mathrm{SiO}_{2}$ & \\
\hline 5 & VO (Iso-OPr) ${ }_{3}$ & Dioxane & $\mathrm{TiO}_{2} / \mathrm{SiO}_{2}\left({ }^{*}\right)$ & \\
\hline 6 & VO (Iso-OPr) ${ }_{3}$ & Isopropanol & $\left.\mathrm{TiO}_{2} / \mathrm{SiO}_{2}{ }^{*}\right)$ & \\
\hline 7 & VO (Iso-OPr) ${ }_{3}$ & n-hexane & $\left.\mathrm{TiO}_{2} / \mathrm{SiO}_{2}{ }^{*}\right)$ & \\
\hline
\end{tabular}
and corresponding test reactions.

(*) Titania grafted on silica surface. The support has been prepared by repeating two or three times the grafting procedure (multi-layers of titania coating silica surface).

\section{The system titania grafted on silica}

Titania has been grafted first of all on silica $\left(450 \mathrm{~m}^{2} / \mathrm{g}\right)$ by changing the alkoxide concentration in toluene [8]. Three different catalysts have been obtained characterized by a different titanium concentrations on the surface that were respectively $0.25,1.16$ and $1.80 \mathrm{mmol} / \mathrm{g}$ corresponding to $2.0,9.3$ and 14.4 weight $\%$ of $\mathrm{TiO}_{2}$. The third value corresponds approximately to a monolayer coverage. Then a multilayer coating had been prepared by repeating three times the grafting procedure on the same sample. In this last case $3.31 \mathrm{mmol} / \mathrm{g}$ of titanium were grafted corresponding to 26.4 weight $\%$ of $\mathrm{TiO}_{2}$. Very singular is the observation that the decrease of the specific surface area as a consequence of the grafting was very low being for the three previously mentioned catalyst 440 , 418 and $400 \mathrm{~m}^{2} / \mathrm{g}$. In conclusion by coating $\mathrm{SiO}_{2}$ with a monolayer of $\mathrm{TiO}_{2}$ we completely changed the surface of the original support obtaining a stable high surface of $\mathrm{TiO}_{2}$. This is an important result considering that the support $\mathrm{TiO}_{2}$ - anatase, obtained by precipitation has a specific surface area never exceeding $80 \mathrm{~m}^{2} / \mathrm{g}$ that strongly decreases for sintering after calcinations.

$\mathrm{TiO}_{2}$ is well known the ideal support for $\mathrm{V}_{2} \mathrm{O}_{5}$, because, the strong interaction with that oxide hinders its agglomeration during ODH reactions. The multilayer $\mathrm{TiO}_{2} / \mathrm{SiO}_{2}$ system has a lower specific surface area of about $350 \mathrm{~m}^{2} / \mathrm{g}$, however, significantly higher than anatase. The change of the acid-base properties has already been considered in the previous chapter considering the performance achieved in the methanol dehydration reaction for a sub-monolayer deposition of titania grafted on silica. Let us consider now the redox 
properties of these catalysts and their utility as support for preparing vanadium based catalysts prepared by grafting vanadyl alkoxides. At this purpose, in Figure 4, the Langmuir isotherm related to the titania grafted on silica, starting from a silica of $282 \mathrm{~m}^{2} / \mathrm{g}$ and $\mathrm{Ti}$ (iso-Propoxide) ${ }_{4}$ solution in dioxane, is reported [10]. In this case, the maximum amount of titanium loaded (monolayer) is $1 \mathrm{mmol} / \mathrm{g}$ instead of $1.8 \mathrm{mmol} / \mathrm{g}$ obtained on a silica of $450 \mathrm{~m}^{2} / \mathrm{g}$ using toluene as solvent. This last silica and the solvent dioxane will be used to prepare the supports for anchoring vanadia.

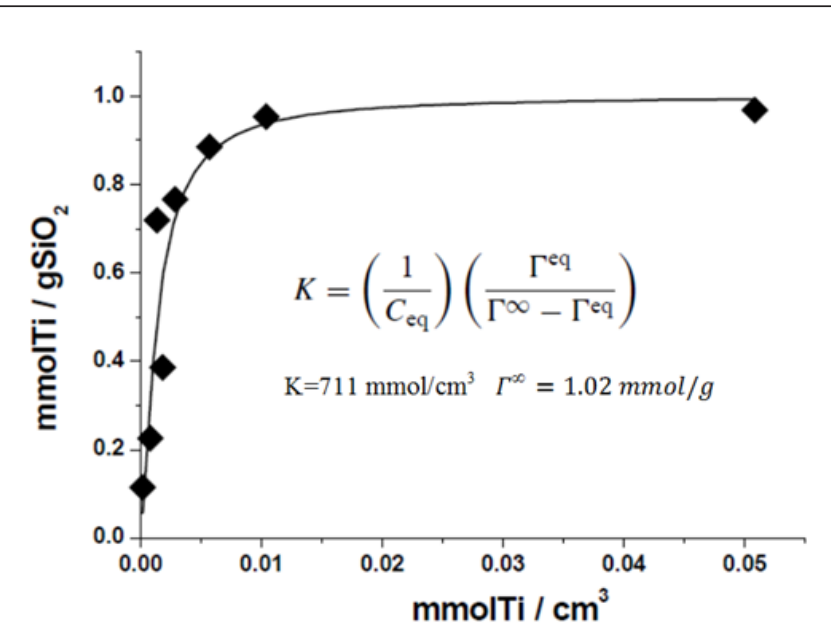

Figure 4: A Langmuir isotherm determined for the chemical adsorption of Ti (iso-Propoxide) ${ }_{4}$, dissolved in dioxane, on a commercial silica of $282 \mathrm{~m}_{2} / \mathrm{g}$ of specific surface area [10].

It must pointed out that, by coating silica with titania, Lewis acid sites of moderate strength appears and increase with the amount of grafted titania until reaching a maximum when a monolayer of titania is deposited on the surface. These sites are responsible of the good performances obtained in two different reactions: the epoxidation of cyclo-octene and the transesterification of triglycerides with methanol (Biodiesel synthesis). By increasing further the amount of deposited titania on silica (multi-layered systems) both the mentioned reactions activity strongly lowered probably, because, new excessively strong Lewis sites not suitable for the mentioned reactions appear on the surface.

\section{The System Vanadia Grafted on Silica/Titania Support}

Different vanadium pentoxide based catalysts have been prepared by grafting vanadyl isopropoxide on respectively: silica, $\mathrm{TiO}_{2} / \mathrm{SiO}_{2}$

A. Silica covered with a monolayer of titania TS1 and silica covered with a multi-layer TS3 (Grafting repeated three times in the same conditions). The amounts of vanadyl alkoxide adsorbed for the different considered supports is compared in Figure 5 [10]. The steep rise of the initial curve related to the TS3 support denotes the strong interactions occurring between vanadyl alkoxide and titania surface with respect to the curve obtained for silica.

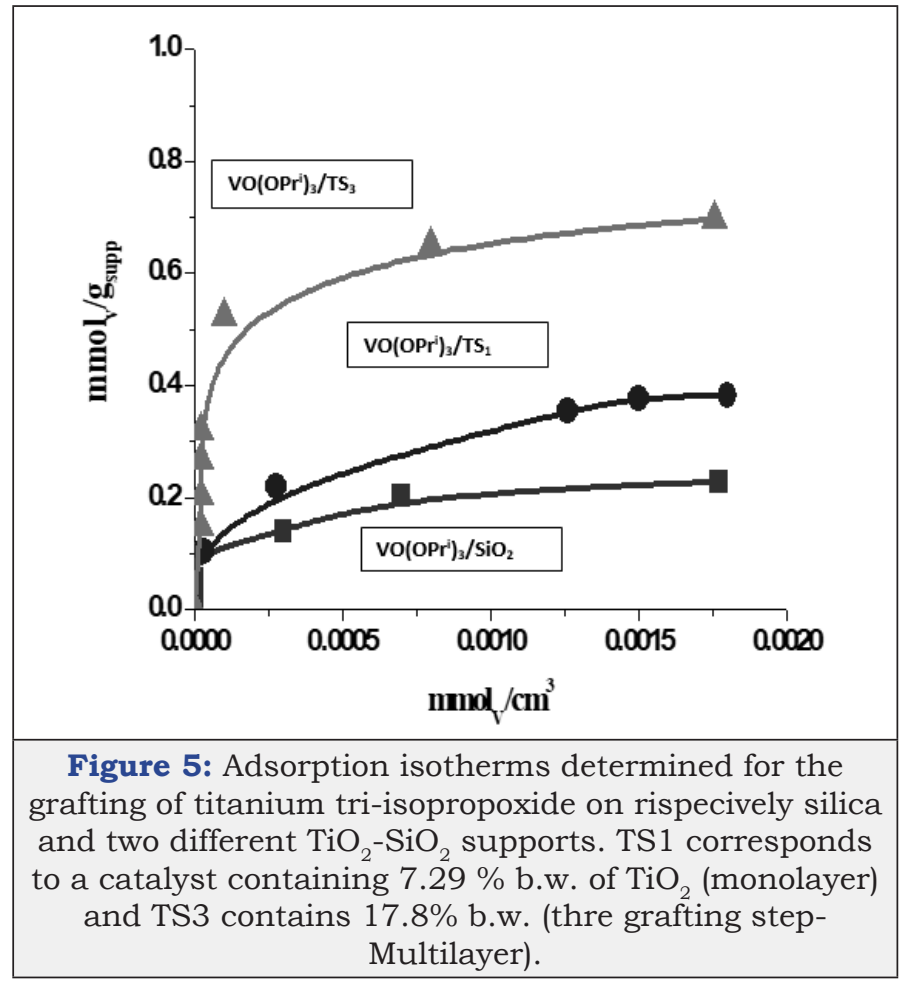

For very low vanadia coverage degree monomeric isolated species are prevalent (Scheme A and B) in agreement with the observation reported in the literature, while, it is interesting to observe that the overall stoichiometry for the monolayer is about $20 \mathrm{H} / \mathrm{V}$. This means that we can have on the surface a mixture of monomeric species A and B and of oligomeric species of the type (C).

Evidenced the presence of a mixture of monomeric and polymeric species with a preminence of the monomeric at the lower coverage degree. However, the polymeric species are, very probably, of linear or planar structure. Spectra give also the evidence of V-OTi bonds with bands at $250-640 \mathrm{~cm}^{-1}$.

\section{Redox reactions test results}

The test reactions considered are:

\section{Cyclo-Octene Epoxydation with Cumene Hydroperox- ide}

The reaction requires redox sites containing titanium $[8,11]$

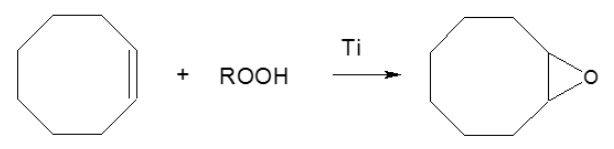

The catalysts employed in this reaction are the ones prepared by using the support silica with $280 \mathrm{~m}^{2} / \mathrm{g}$ coated with increasing amounts of titanium alkoxide dissolved in toluene until reaching the monolayer and a catalyst. The obtained results are reported in Figure 6. 


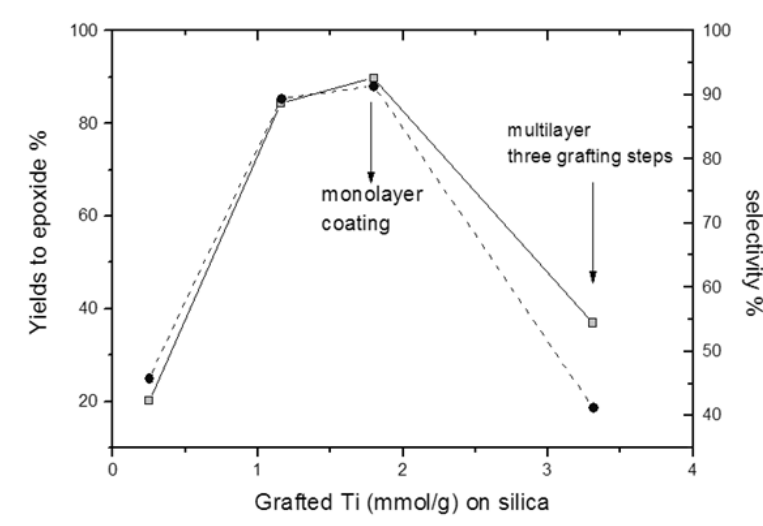

Figure 6: Cyclooctene epoxidation by cumene hydroperoxide in th presence of $\mathrm{TiO}_{2}-\mathrm{SiO}_{2}$ catalysts containing different amount of grafted titania.

As it can be seen the activity and selectivity increase with the content of $\mathrm{TiO}_{2}$ until reaching a maximum for the catalyst charged with a monolayer of titanium alkoxide. This maximum coincides with the maximum of Lewis acid sites concentration on the surface as shown in the work published by Cozzolino et al. [12].

\section{Selective Catalytic Reduction (SCR) of $\mathrm{NO}_{\mathrm{x}}$ with $\mathrm{NH}_{3}$}

The SCR reaction:

$\mathrm{NH}_{3}+\mathrm{NO}+1 / 4 \mathrm{O}_{2} \rightarrow \mathrm{N}_{2}+3 / 2 \mathrm{H}_{2} \mathrm{O}$

Was performed on $\mathrm{V}_{2} \mathrm{O}_{5}$ containing catalysts, supported on a $\mathrm{TiO}_{2}$ surface [13]. Two catalysts have been tested one prepared by grafting vanadyl tri-isopropoxide on a commercial $\mathrm{TiO}_{2}$ having a specific surface area of $120 \mathrm{~m}^{2} / \mathrm{g}$ that has been compared with a catalyst prepared by impregnating vanadium on the same support. Another catalyst has been prepared starting from $\mathrm{TiO}_{2} / \mathrm{SiO}_{2}$ support (a silica coated with multi-layers of $\mathrm{TiO}_{2}$ repeating three time the grafting procedure of titanium tri- isopropoxide dissolved in toluene on a silica support of $280 \mathrm{~m}^{2} / \mathrm{g}$ ).

Table 3: List of the used support and catalysts in the SCR of $\mathrm{NO}_{\mathrm{x}}$ with $\mathrm{NH}_{3}$.

\begin{tabular}{|c|c|c|c|c|c|c|}
\hline Sample & $\mathbf{V}_{\mathbf{2}} \mathbf{O}_{\mathbf{5}}$ (wt. \%) & BET Surface $\left(\mathbf{m}^{2} / \mathbf{g}\right)$ & Vox Density Vox $/ \mathbf{n m}^{2}$ & $\mathbf{T}\left({ }^{\circ} \mathbf{C}\right)$ & NO Conversion $(\mathbf{\%})$ & $\mathbf{N}_{\mathbf{2}} \mathbf{O}(\%)$ \\
\hline $\mathrm{V}_{2} \mathrm{O}_{5} \mathrm{impr} / \mathrm{TiO}_{2}$ & 6 & 62 & 6.4 & 350 & 95 & 8.3 \\
\hline $\mathrm{V}_{2} \mathrm{O}_{5} \mathrm{graf} / \mathrm{TiO}_{2}$ & 5.3 & 70 & 5 & 420 & 47 & 0 \\
\hline $\mathrm{V}_{2} \mathrm{O}_{5} \mathrm{impr} / \mathrm{TiO}_{2} / \mathrm{SiO}_{2}$ & 6 & 240 & 1.7 & 401 & 72 & 8 \\
\hline $\mathrm{V}_{2} \mathrm{O}_{5} \mathrm{graf} / \mathrm{TiO}_{2} / \mathrm{SiO}_{2}$ & 6 & 200 & 1.9 & 350 & $>99$ & 0 \\
\hline
\end{tabular}

The same catalyst has then been compared with a catalyst prepared by impregnation containing the same amount of supported vanadium. The data of conversions in the mentioned reaction have been collected in steady state conditions and are reported in Table 3. As it can be seen, the specific surface area of titania decreased very much as a consequence of the treatments of impregnation, grafting and calcinations. However, although the activity of the catalyst grafted on $\mathrm{TiO}_{2}$ is lower its selectivity is greater. On the contrary, the activity and selectivity of the catalyst prepared by grafting vanadyl tri-isopropoxide on the described $\mathrm{TiO}_{2} / \mathrm{SiO}_{2}$ support are both much greater.

This can be better appreciated from the plots reported in Figure 7.

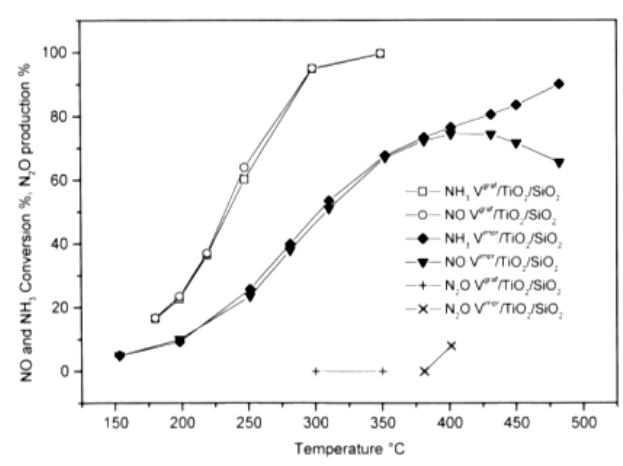

Figure 7: $\mathrm{NO}$ and $\mathrm{NH}_{3}$ conversions as a function of the temperature. A comparison between a two $\mathrm{V}_{2} \mathrm{O}_{5} /$ $\mathrm{TiO}_{2}-\mathrm{SiO}_{2}$ catalysts one prepared by wet impregnation of ammonia metavanadate and another one by grafting vanadyl isopropoxide on the same $\mathrm{TiO}_{2}-\mathrm{SiO}_{2}$ support.

\section{High temperature ODH (Oxidative dehydrogenation) reactions}

The reaction considered in a general approach is:

$$
\mathrm{C}_{\mathrm{n}} \mathrm{H}_{2 \mathrm{n}+2}+1 / 2 \mathrm{O}_{2} \rightarrow \mathrm{C}_{\mathrm{n}} \mathrm{H}_{2 \mathrm{n}}+\mathrm{H}_{2} \mathrm{O}(19)
$$

As alkanes have been tested: propane [14], Butane [15] and Isobutane [16] for obtaining the corresponding olefins. The most relevant results have been obtained in the ODH of butane. The best catalysts used for promoting this reaction [15] are reported in Table 4.

Table 4: List of the catalysts tested in the ODH of n-butane to butenes.

\begin{tabular}{|c|c|c|c|}
\hline Catalyst & Wt. $\% \mathbf{V}_{\mathbf{2}} \mathbf{O}_{\mathbf{5}}$ & $\mathbf{V}(\mathbf{m m o l} / \mathbf{g})$ & SBET $\left(\mathbf{m}^{2} / \mathbf{g}\right)$ \\
\hline $\mathrm{V}_{2} \mathrm{O}_{5} / \mathrm{TiO}_{2} / \mathrm{SiO}_{2}$ & 1.35 & 0.15 & 278 \\
\hline $\mathrm{V}_{2} \mathrm{O}_{5} / \mathrm{TiO}_{2} / \mathrm{SiO}_{2}$ & 2.92 & 0.32 & 272 \\
\hline $\mathrm{V}_{2} \mathrm{O}_{5} / \mathrm{TiO}_{2} / \mathrm{SiO}_{2}$ & 4.78 & 0.53 & 262 \\
\hline $\mathrm{V}_{2} \mathrm{O}_{5} / \mathrm{TiO}_{2} / \mathrm{SiO}_{2}$ & 5.92 & 0.65 & 248 \\
\hline $\mathrm{V}_{2} \mathrm{O}_{5} / \mathrm{TiO}_{2} / \mathrm{SiO}_{2}$ & 11.08 & 1.2 & 235 \\
\hline
\end{tabular}

In all cases reported in Table 4, vanadyl tri-isopropoxide dissolved in dioxane has been grafted on a support prepared by grafting titanium tetra-isopropoxide dissolved in toluene on a commercial silica of $320 \mathrm{~m}^{2} / \mathrm{g}$ and repeating three time the grafting procedure to obtain a silica coated with a multilayer of $\mathrm{TiO}_{2}$ (2.23mmols of $\mathrm{Ti}$ anchored/g corresponding to $17.8 \%$ of $\mathrm{TiO}_{2}$ ). The surface area of the $\mathrm{TiO}_{2}-\mathrm{SiO}_{2}$ support was $274 \mathrm{~m}^{2} / \mathrm{g}$. The catalytic tests have been performed at atmospheric pressure in a quartz 
tube microreactor containing small amount of catalyst (0.015-0.05 g) and feeding butane diluted with helium and oxygen. The total feed flow rate was kept between 50 and $200 \mathrm{~cm}^{3} /$ minute and the $\mathrm{O}_{2}$ /butane ratio was kept equal to 1.7 .

At the exit the gaseous stream was analyzed by gaschromatography for determining residual oxygen and butane, other formed hydrocarbons, $\mathrm{CO}$ and $\mathrm{CO}_{2}$. The temperature of the reactor was kept constant, in all cases, at $500{ }^{\circ} \mathrm{C}$. Different runs have been made by using not only the catalysts of Table 4 . But also catalyst prepared by impregnation on silica, on titania and on $\mathrm{TiO}_{2}-\mathrm{SiO}_{2}$ support and also by grafting vanadyl tri-isopropoxide on silica. In all these last mentioned cases the activity and selectivity was dramatically low if compared with the performances of the catalysts of Table 4. A comparison of the activity and selectivity obtained on catalysts prepared respectively by grafting vanadyl triisopropoxide on silica and on two different $\mathrm{TiO}_{2}-\mathrm{SiO}_{2}$ supports, one containing approximately a monolayer of grafted titanium alkoxide (TS1) and another obtained by repeating the grafting procedure three times (TS3). The difference in the obtained activities and selectivities can be appreciated in Figure 8.
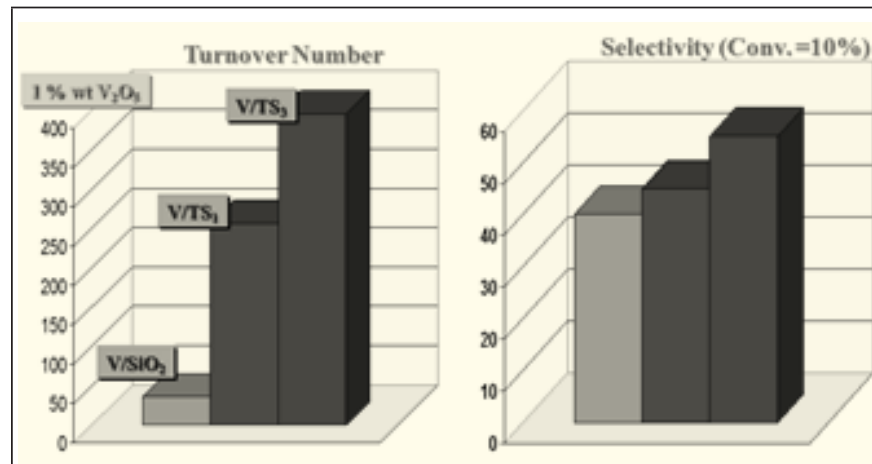

Figure 8: A comparison of activities and selectivity obtained on three different described catalysts in the ODH of butane.
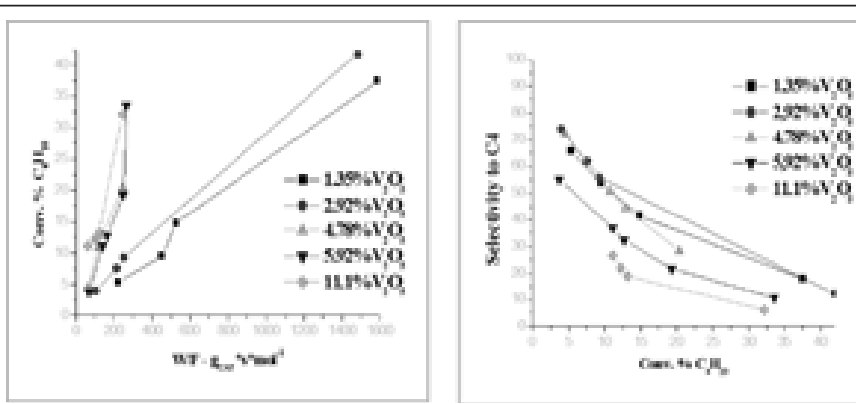

Figure 9: The activities and selectivities obtained at different residence times for the catalysts of Table 4 containing increasing amounts of grafted $\mathrm{V}_{2} \mathrm{O}_{5}$.

In Figure 9 the conversions and selectivities obtained for the different tested catalysts of Table 4 are reported as a function of the residence time W/F. As it can be seen, while the conversion increases almost linearly with the amount of loaded $\mathrm{V}_{2} \mathrm{O}_{5}$, the selectivity is higher for the lower vanadium loaded catalysts that are more disperse and reach of monomeric vanadium species. The yield shows a maximum for the catalyst containing $4.78 \%$ b.w of vanadia.

\section{Low temperature ODH (Oxidative dehydrogenation) reactions}

Methanol and ethanol are easily oxidized to the corresponding aldehydes by catalysts containing $\mathrm{V}_{2} \mathrm{O}_{5}$ on the surface. Again, catalyst prepared by grafing vanadyl tri-isopropoxide on $\mathrm{TiO}_{2}$ $\mathrm{SiO}_{2}$ support, similar to the ones used in the previous example, confirmed their exceptional properties characterized by very high activity, selectivity and stability. These reactions occur at relatively low temperatures, in the range of $150-250{ }^{\circ} \mathrm{C}$.

In the case of methanol oxidation to formaldehyde $[17,18]$, we can write:

$\mathrm{CH}_{3} \mathrm{OH}+1 / 2 \mathrm{O}_{2} \rightarrow \mathrm{CH}_{2} \mathrm{O}+\mathrm{H}_{2} \mathrm{O}(20)$

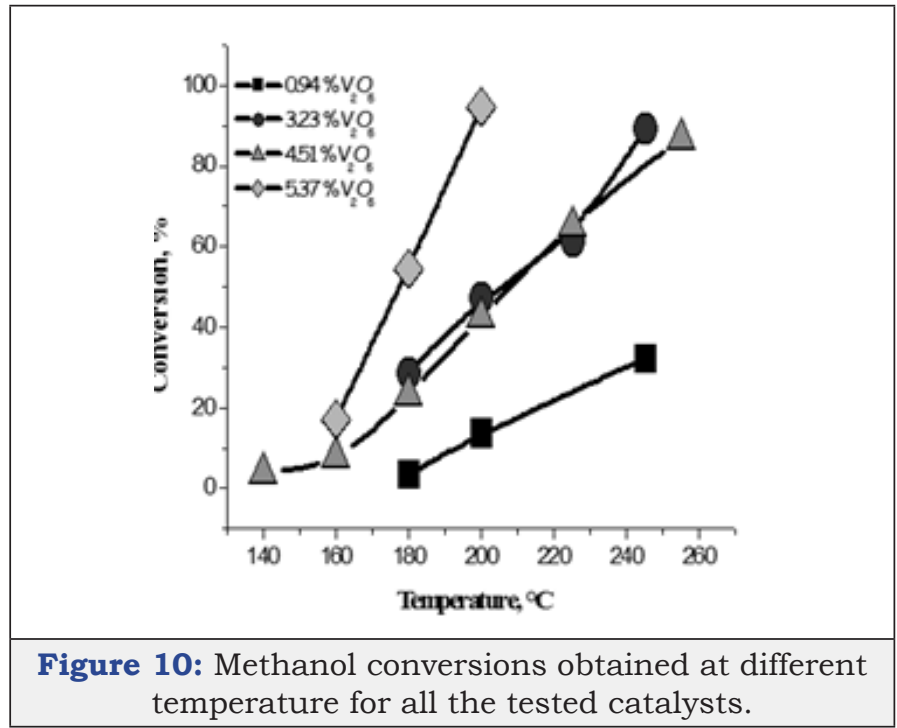
temperature for all the tested catalysts.

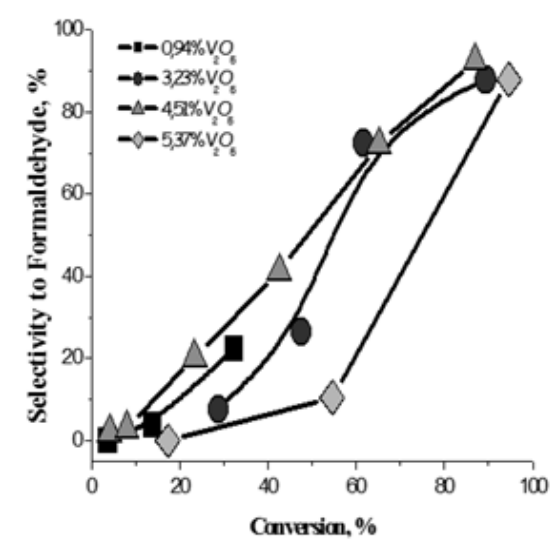

Figure 11: Selectivity obtained for all the tested catalysts as a function methanol conversion.

The best catalyst for promoting this reaction resulted the one prepared by grafting vanadyl vanadyl tri-isopropoxide dissolved in dioxane on $\mathrm{TiO}_{2}-\mathrm{SiO}_{2}$ (silica coated with a monolayer of titania). 
The titania grafted on the silica support was $7.3 \mathrm{w} \%$ with a specific surface area of $278 \mathrm{~m}^{2} / \mathrm{g}$. Catalysts containing different amounts of grafted vanadia have been prepared and tested in an isothermal tubular reactor by feeding, at atmospheric pressure methanol, (20mol\%), oxygen $(20 \mathrm{~mol} \%)$ ansd Helium (60mol\%). The amount of catalyst put in the reactor was $0.5 \mathrm{~g}$ and the residence time $\mathrm{W} /$ $\mathrm{F}=25.3$ ( $\mathrm{gh} / \mathrm{mol}$ of methanol). The temperature range was kept $140-260{ }^{\circ} \mathrm{C}$. The obtained results can be appreciated in Figures 10 $\& 11$.

As it can be seen, the activity increases with both the temperature and the vanadium load. Then, by comparing the performances of the best catalyst containing $5.37 \%$ of vanadia with an industrial catalyst, normally employed for promoting this reaction and based on iron molibdate the same conversion and selectivity is obtained at respectively $220^{\circ} \mathrm{C}$ for vanadia based catalyst, while, $280{ }^{\circ} \mathrm{C}$ were necessary for the iron molibdate catalyst.

At last, on the best catalyst, that is, the one containing $5.37 \mathrm{w} \%$ of vanadia a kinetic approach has been developed determining the reaction products observed at different reaction temperatures. $\mathrm{T}$ the obtained results are reported in Figure 12. As it can be seen, by increasing the temperature the formation of intermediate products as dimethoxy methane and methylformate are observed. Further increasing the temperature these two products completely disappears, while, the formation of $\mathrm{CO}_{2}$ increases.

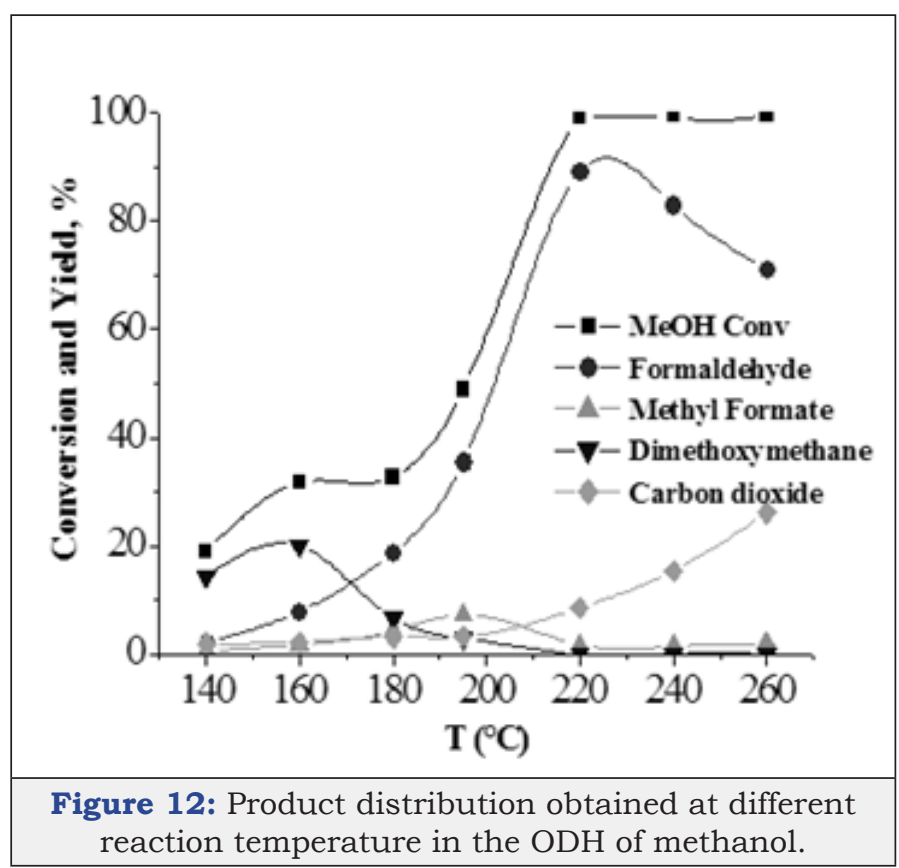

More instructive is the evolution of the product distribution as a function of the residence time $\mathrm{W} / \mathrm{F}$, at $160{ }^{\circ} \mathrm{C}$, reported in Figure 13. More details about this study can be found in [17] in which a reaction mechanism is proposed and a kinetic model for interpreting all the kinetic runs performed is described.
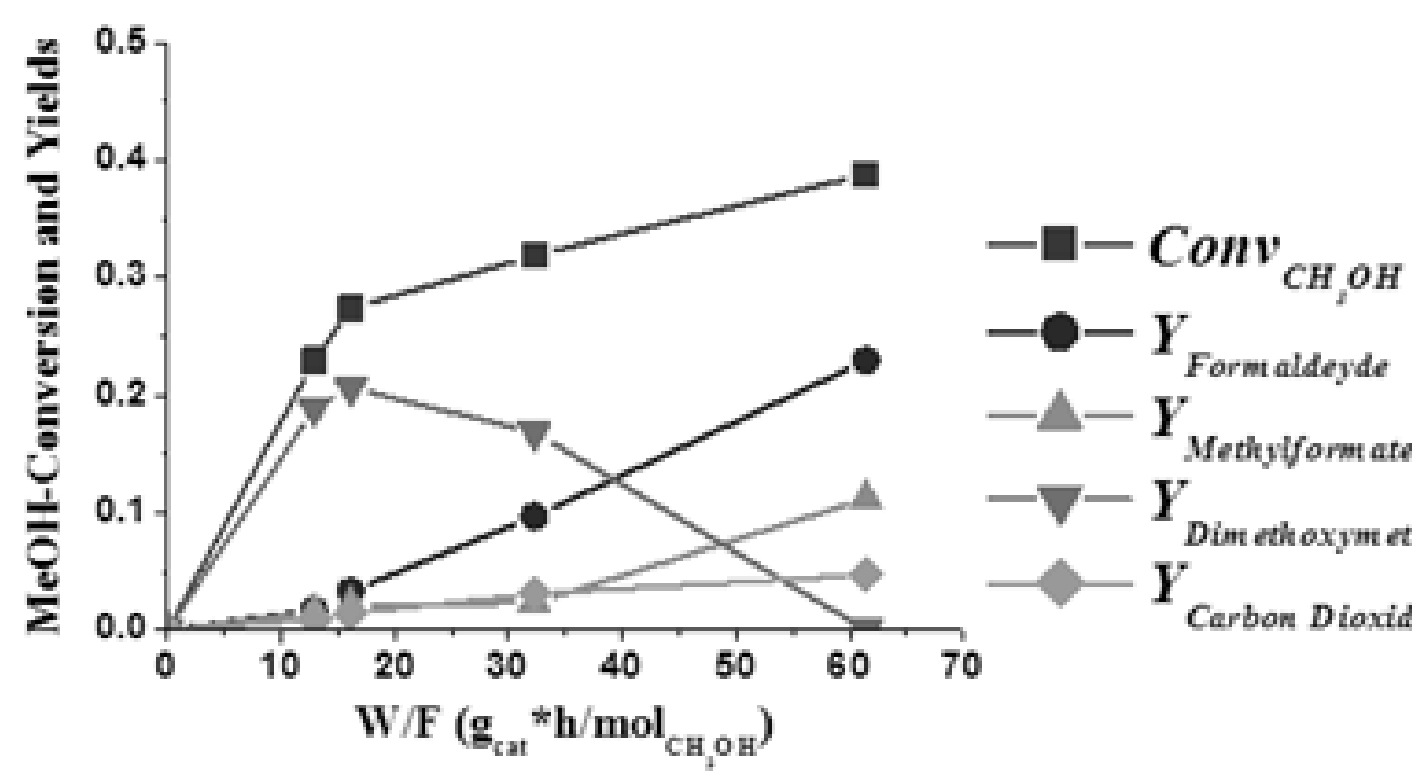
$-\mathrm{O}-\boldsymbol{Y}_{\text {Formaldeyde }}$ $-\Delta-\boldsymbol{Y}_{\text {Methylform ate }}$ $-\nabla-Y_{\text {Dim ethoxym ethane }}$ $-\boldsymbol{Y}$ Carbon Dioxide

Figure 13: Methanol conversion and product distribution, at $160{ }^{\circ} \mathrm{C}$, in the $\mathrm{ODH}$ of methanol as a function of the residence time. Run performed by using a vanadia catalyst grafted on $\mathrm{TiO}_{2}-\mathrm{SiO}_{2}$ support $(5.37 \%$ vanadia/7.3\% titania/ $\mathrm{SiO}_{2}$ ).

In the case of ethanol oxidation to acetaldehyde $[19,20]$, we can write:

$$
\mathrm{C}_{2} \mathrm{H}_{5} \mathrm{OH}+1 / 2 \mathrm{O}_{2} \rightarrow \mathrm{CH}_{3} \mathrm{CHO}+\mathrm{H}_{2} \mathrm{O}(21)
$$

Also this reaction is promoted by supported $\mathrm{V}_{2} \mathrm{O}_{5}$ and again catalysts prepared by grafting are more selective than the ones prepared by impregnation as it can be appreciated in Figure 14 . 


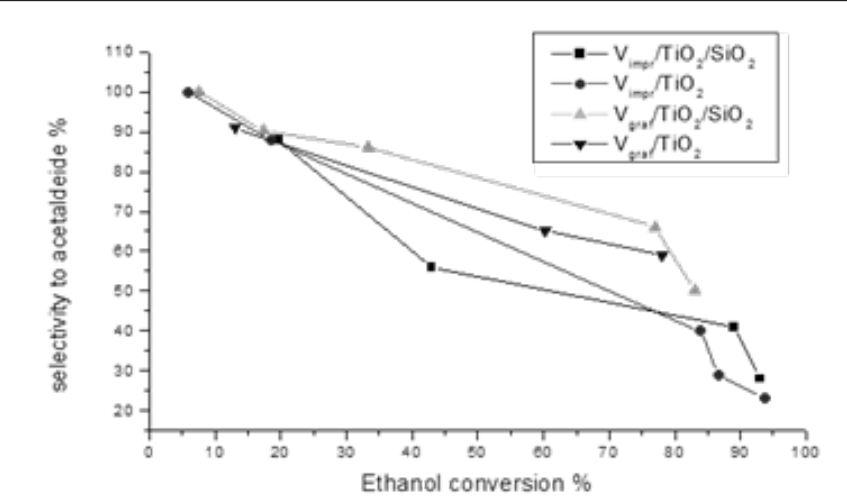

Figure 14: A comparison of the selectivities respectively obtained in the ODH of ethanol by using impregnated and grafted vanadia catalysts using as supports $\mathrm{TiO} 2$ and $\mathrm{TiO}_{2}-\mathrm{SiO}_{2}$.

The conversion and yields obtained at respectively 140 and 160 ${ }^{\circ} \mathrm{C}$ with the vanadium grafted best catalyst are reported in Figures $15 \& 16$, while the product distribution obtained at $160^{\circ} \mathrm{C}$ is reported in Figure 17. Also in this case, a reaction mechanism has been proposed and a Mars-Krevelen kinetic model has been developed for interpreting all the experimental runs and determining the best fitting parameters [20].
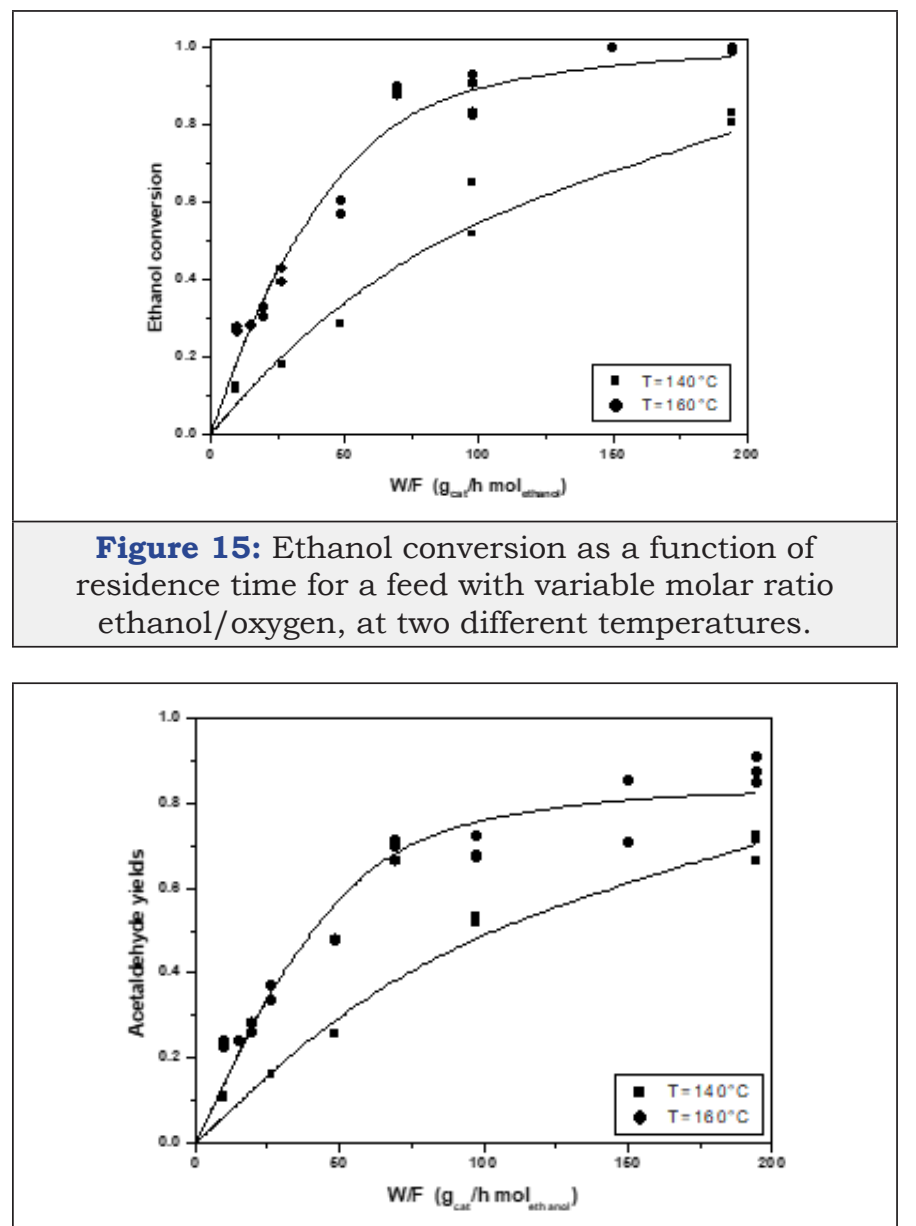

Figure 16: Acetaldehyde yields as a function of residence time for a feed with variable molar ratio ethanol/oxygen, at different temperatures.

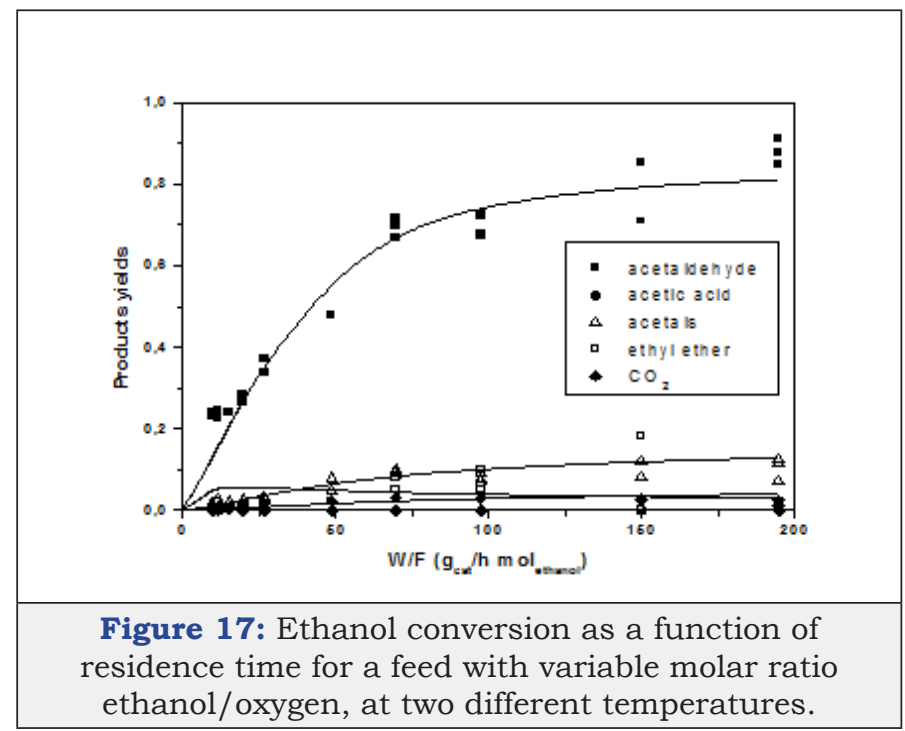

\section{Conclusion}

Some different and new insights have been achieved in this work and many others have been confirmed the beneficial use of the grafting technique. This method appears very appealing not only to modify the chemical acid-base and/or redox properties of a surface but also to prepare supports and catalysts with very high dispersion. The surfaces of a support modified by grafting alkoxides, after steaming and calcinations show properties that are different from both the original support and the coating oxide. Many of the catalysts prepared by grafting alkoxides on the surface of oxides have surprisingly shown peculiar catalytic properties. In particular, titania deposited by grafting titanium alkoxide on silica, in a small amount, has shown catalytic properties as both acid-base catalyst in methanol dehydration and redox catalyst in cyclo-octene epoxidation.

By grafting more titanium alkoxide on silica until reaching a monolayer or repeating more time the grafting procedure depositing multi-layers of $\mathrm{TiO}_{2}$ on silica a new very interesting support is obtained, because, the specific surface of silica is reduced for a small extent and we have so a large $\mathrm{TiO}_{2}$, surface that is stable to the heat treatments differently from the anatase surface that in the same conditions is prone to collapse. This support is very suitable to the preparation of vanadium based dispersed catalysts being the vanadium pentoxide-titania interactions very strong [21]. These catalysts have given very promising results in the ODH of hydrocarbons to olefins and to the ODH of methanol and ethanol to the corresponding aldehydes.

\section{References}

1. Bradley DC (1989) Metal alkoxides as precursors for electronic and ceramic materials. Chem Rev 89(6): 1317-1322.

2. Bradley DC, Mehrotra RC, Gaur DP. Metal Alkoxides, Academic Press, USA.

3. Mehrotra RC, Singh A, Sogani S (1994) Chem Rev 94: 1643-1660.

4. Peri B (1965) A model for the surface of alumina. J Phys Chem 69(1): 220-230. 
5. Tanabe K (1970) Solid acids and bases, Kodansha Tokio and Academic Press.

6. Iengo P, Di Serio M, Sorrentino A, Solinas V, Santacesaria E (1998) Preparation and properties of new acid catalysts obtained by grafting alkoxides and derivatives on the most common supports. Note IGrafting aluminum and zirconium alkoxides and related sulphates on silica. Applied Catalysis A 167: 85-101.

7. Iengo P, Di Serio M, Solinas V, Gazzoli D, Salvio G, et al. (1998) Preparation and properties of new acid catalysts obtained by grafting alkoxides and derivatives on the most common supports. Note II- Grafting silicon and zirconium alkoxides and related sulphates on $\gamma$-alumina. Applied Catalysis A: General 170: 225-244.

8. Iengo P, Di Serio M, Gazzoli D, Aprile G, Santacesaria E (1999) Preparation and properties of new acid catalysts obtained by grafting alkoxides and derivatives on the most common supports. Note III- Grafting titanium and vanadil alkoxides on silica. Applied Catalysis A: General 178: 97-109.

9. Rulkens R, Bell A, Iglesia E, Don Tilley T (1999) Vanadyl tert-Butoxy Orthosilicate, OV $\left[\mathrm{OSi}\left(\mathrm{O}^{\mathrm{t}} \mathrm{Bu}\right)_{3}\right]_{3}$ : A Model for Isolated Vanadyl Sites on Silica and a Precursor to Vanadia-Silica Xerogels. Chem Mater 1: 29662973.

10. Santacesaria E, Cozzolino M, Di Serio M, Venezia AM, Tesser R (2004) Vanadium based catalysts prepared by grafting: preparation, properties and performances in the ODH of butane. App Catal A: General 270: 177 192.

11. Cozzolino M, Di Serio M, Tesser R, Santacesaria E (2007) Grafting of titanium alkoxides on high-surface $\mathrm{SiO}_{2}$ support: An advanced technique for the preparation of nanostructured $\mathrm{TiO}_{2} / \mathrm{SiO}_{2}$ catalysts; Applied Catalysis A: General 325(2): 256-262.

12. Cozzolino M, Tesser R, Di Serio M, Gaigneaux EM, Eloy P, et al. (2006) Supported vanadium oxide nanoparticles: effects of preparation method, support and type of precursor on the catalytic performances in the ODH of methanol to formaldehyde. Studies in Surface Science and Catalysis in Scientific Bases for Preparation of Heterogeneous Catalysts 162: 697-704.

13. Sorrentino A, Rega S, Sonnino D, Magliano A, Ciambelli P, et al. (2001) Performances of $\mathrm{V}_{2} \mathrm{O}_{5}$-based catalysts obtained by grafting vanadyl tri- isopropoxide on $\mathrm{TiO}_{2}-\mathrm{SiO}_{2}$ in SCR. Applied Catalysis A: General 209: 4557.

14. Comite A, Sorrentino A, Capannelli G, Di Serio M, Tesser R, et al. (2003) Oxidative dehydrogenation of propane using $\mathrm{V}_{2} \mathrm{O}_{5} / \mathrm{TiO}_{2} / \mathrm{SiO}_{2}$ catalysts prepared by grafting titanium and vanadium alkoxides on silica. Journal of Molecular Catalysis A: Chemical 198(1-2): 151-165.

15. Santacesaria E, Cozzolino M, Di Serio M, Venezia AM, Tesser R (2004) Vanadium based catalysts prepared by grafting: preparation, properties and performances in the ODH of butane. Applied Catalysis, A: General 270(1-2): 177-192.

16. Iannazzo V, Neri G, Galvagno S, Di Serio M, Tesser R, et al. (2003) Oxidative dehydrogenation of isobutane over $\mathrm{V}_{2} \mathrm{O}_{5}$-based catalysts prepared by grafting vanadyl alkoxides on $\mathrm{TiO}_{2}-\mathrm{SiO}_{2}$ supports. Applied Catalysis A: General 246(1): 49-68.

17. Cozzolino M, Tesser R, Di Serio M, D’Onofrio P, Santacesaria E (2007) Kinetics of the oxidative dehydrogenation $(\mathrm{ODH})$ of methanol to formaldehyde by supported vanadium-based nanocatalysts. Catalysis Today 128(3-4): 191-200.

18. Cozzolino M, Tesser R, Di Serio M, Santacesaria E (2005) Methanol and ethanoloxidative dehydrogenation (ODH) to the corresponding aldehydes on vanadium-based catalysts. DGMK Tagungsbericht; Proceedings of the DGMK/SCI-Conference. Oxidation and Functionalization: Classical and Alternative Routes and Sources, pp. 91-98.

19. Santacesaria E, Sorrentino A, Tesser R, Di Serio M, Ruggiero A (2003) Oxidative dehydrogenation of ethanol to acetaldehyde on $\mathrm{V}_{2} \mathrm{O}_{5} / \mathrm{TiO}_{2}-\mathrm{SiO}_{2}$ catalysts obtained by grafting vanadium and titanium alkoxides on silica. Journal of Molecular Catalysis A: Chemical 204(205): 617-627.

20. Tesser R, Maradei V, Di Serio M, Santacesaria E (2004) Kinetics of the Oxidative Dehydrogenation of Ethanol to Acetaldehyde on $\mathrm{V}_{2} \mathrm{O}_{5} / \mathrm{TiO}_{2}$ $\mathrm{SiO}_{2}$ Catalysts Prepared by Grafting. Industrial \& Engineering Chemistry Research 43(7): 1623-1633.

21. Wachs IE, Weckhuysen BM (1997) Structure and reactivity of surface vanadium oxide species on oxide supports. Appl Catal A: General 157: 67-90.

For possible submissions Click below:

Submit Article 